\title{
Isosorbide-5-mononitrate in the treatment of pulmonary hypertension associated with portal hypertension
}

\author{
J. Ribas, J. Angrill, J.A. Barberà, J.C. García-Pagán, J. Roca, J. Bosch, R. Rodriguez-Roisin
}

\begin{abstract}
Isosorbide-5-mononitrate in the treatment of pulmonary hypertension associated with portal hypertension. J. Ribas, J. Angrill, J.A. Barberà, J.C. Garcá-Pagán, J. Roca, J. Bosch, R. Rodriguez-Roisin. (C)ES Journals Ltd 1999.

ABSTRACT: Pulmonary hypertension is uncommonly associated with portal hypertension. The current approach for the management of pulmonary hypertension involves the use of vasodilators in patients who show vascular responsiveness during an acute challenge. Since the association of portal hypertension with pulmonary hypertension is very seldomly presented, its optimal therapy has not been defined. Moreover, calcium-channel blockers, which are usually used in pulmonary hypertension treatment, may exert a deleterious effect on portal hypertension. Therefore, the search for drugs that may be active under both conditions has important clinical implications.

This report presents the case of a patient with portal hypertension-as sociated pulmonary artery hypertension that was effectively treated with isosorbide-5mononitrate (Is-5-Mn). The patient had severe portal hypertension (hepatic venous pressure gradient $=14.5 \mathrm{mmHg}$ ) and pulmonary hypertension (mean pulmonary artery pressure $(P A P)=50 \mathrm{mmHg})$. Acute administration of prostacyclin and nitric oxide elicited a significant reduction in both PAP and pulmonary vascular resistance (PVR), an effect that was also achieved with Is-5-Mn. The patient was treated with 40 mg Is-5-Mn twice daily and a haemodynamic study performed 6 months later showed that the reduction in both PAP and PVR persisted.
\end{abstract}

Eur Respir J 1999; 13: 210-212.

Serveis de Pneumologia i Al·lèrgia Respiratòria i d"Hepatologia, Dept de Medicina, Hospital Clnic,Universitat de Barcelona, Spain.

Correspondence: J.A. Barberà

Servei de Pneumologia i Al-lèrgia

Respiratòria

Hospital Clínic

Villarroel 170

08036 Barcelona

Spain

Fax: 34932275455

Keywords: Isosorbide

nitric oxide

portal hypertension

prostacyclin

pulmonary hypertension

Received: January 151998

Accepted after revision August 061998
Patients with portal hypertension of varying aetiology may develop pulmonary hypertension [1]. The mechanisms of such an association remain obscure and its prognosis is poor. Pulmonary hypertension in patients with portal hypertension-associated pulmonary artery hypertension (PHPAH) does not resolve in all patients after liver transplantation. Furthermore, perioperative management of these patients during liver transplantation is difficult [2]. Since vasodilator treatment in patients with primary pulmonary hypertension who respond to an acute challenge improves prognosis [3], treatment of patients with PHPAH with drugs shown to be effective in lowering both pulmonary and portal hypertension seems reasonable. Calcium-channel blockers, which are commonly used in the treatment of primary pulmonary hypertension [3], exert no beneficial effect on portal hypertension [4]. Nifedipine may actually increase the hepatic venous pressure gradient in patients with portal hypertension [5]. Long-acting organic nitrates are commonly used in the treatment of portal hypertension and they have been shown to reduce acutely [6], but not chronically [7], pulmonary artery pressure (PAP) in patients with normal baseline PAP. Nevertheless, their long-term effect on PAP in patients with pulmonary hypertension is unknown. This study reports the case of a patient with PHPAH and the results of acute vasodilator testing with $i . v$. prostacyclin, inhaled nitric oxide (NO) and oral isosorbide-5-mononitrate (Is-5-Mn). Acute and chronic administration of Is-5-Mn resulted in a significant improvement in both pulmonary and portal hypertension.

\section{Case report}

A 53-yr-old female with portal hypertension secondary to chronic virus $\mathrm{C}$ hepatitis was found to have pulmonary hypertension at rest during hepatic catheterization for the study of portal hypertension (mean PAP was $50 \mathrm{mmHg}$; hepatic venous pressure gradient was $14.5 \mathrm{mmHg}$ ). She smoked 15 cigarettes day $^{-1}$ and had no history of alcohol misuse. The patient had mild exertional dyspnoea (New York Heart Association class II). She denied cough, sputum production and syncope. A chest radiograph was normal and a perfusion radionuclide lung scan ruled out segmental perfusion defects. Echocardiography revealed a mild-tomoderate dilation of the right ventricle and a mild hypertrophy of the right ventricular wall. Forced spirometry and body plethysmography showed normal results (forced expiratory volume in one second (FEV1) was $1.79 \mathrm{~L}(83 \%$ predicted), forced vital capacity (FVC) was $2.26 \mathrm{~L}(80 \%$ pred), FEV1/FVC ratio was $79 \%$ and total lung capacity was $4.44 \mathrm{~L}$ (94\% pred)). The single-breath CO diffusing capacity was $73 \%$ pred. Arterial blood gases, sampled 
while breathing room air, showed the following values: arterial oxygen tension $\left(\mathrm{Pa}_{\mathrm{a}} \mathrm{O}_{2}\right)$ was $9.6 \mathrm{kPa}$, arterial carbon dioxide tension $\left(\mathrm{Pa}_{\left.\mathrm{a}, \mathrm{CO}_{2}\right)}\right)$ was $4.1 \mathrm{kPa}$ and alveolar-arterial pressure difference for oxygen $\left(P \mathrm{~A}-\mathrm{a}, \mathrm{O}_{2}\right)$ was $5.5 \mathrm{kPa}$. An electrocardiogram showed an incomplete right bundle branch block, without signs of right ventricular hypertrophy. A high-resolution computed tomography scan of the chest revealed no abnormalities in the lung parenchyma.

The patient underwent an acute test of pulmonary vascular reactivity in an intensive care unit. A Swan-Ganz catheter was inserted through a femoral vein and pressures were monitored. A radial artery catheter was inserted for the measurement of arterial blood gases. Haemodynamic measurements confirmed pulmonary hypertension, with a normal pulmonary capillary wedge pressure $(P \mathrm{pcw})$ and a mildly reduced cardiac index $(\mathrm{CI})$ : mean PAP was 50 $\mathrm{mmHg}$, mean $P$ pcw was $11 \mathrm{mmHg}$, cardiac output was 4.10 $\mathrm{L} \cdot \mathrm{min}^{-1}$, CI was $2.79 \mathrm{~L} \cdot \mathrm{min}^{-1} \cdot \mathrm{m}^{-2}$, pulmonary vascular resistance (PVR) was 760 dynes $\cdot \mathrm{s} \cdot \mathrm{cm}^{-5}$ and mean right arterial pressure was $8 \mathrm{mmHg}$. Baseline measurements and results of the acute vasodilator test with i.v. prostacyclin, inhaled NO and oral Is-5-Mn are shown in table 1. A significant reduction ( $>30 \%$ from baseline) in PVR was obtained with prostacyclin and NO. One hour after administration, Is-5-Mn caused a reduction of $28 \%$ from baseline in both PAP and PVR. All three vasodilators decreased the mean PAP to similar levels. Pulmonary gas exchange remained unaltered. On the basis of this response, chronic therapy with Is-5-Mn, at a dose of $40 \mathrm{mg}$ twice daily, was initiated. Anticoagulant therapy was not prescribed because of the presence of oesophageal varices. The patient experienced greater exercise tolerance, and at 6 months of follow-up the patient was doing well, without apparent side-effects from the treatment. A second hepatic and rightheart catheterization performed after 6 months of treatment revealed a persistent beneficial effect on pulmonary haemodynamics (mean PAP was $35.5 \mathrm{mmHg}$ and PVR was 459 dynes $\left.\cdot \mathrm{s} \cdot \mathrm{cm}^{-5}\right)$, and a reduction in hepatic venous pressure gradient $(9 \mathrm{mmHg})$. Interestingly, the fall in PAP and PVR shown during the second haemodynamic study after continuous treatment, was of the same magnitude as that achieved during the acute test of pulmonary vascular reactivity.

\section{Discussion}

The association between portal hypertension and pulmonary hypertension has been recognized for a long time. In these cases, liver cirrhosis is the most frequent cause of portal hypertension [8, 9]. Morphologically, PHPAH commonly has a plexogenic appearance on histological examination, although thrombosis may also contribute to vascular obstruction [10]. Findings on chest radiography are similar to those of patients with primary pulmonary hypertension [11].

Management of patients with PHPAH is difficult and the role of liver transplantation in this entity has yet to be defined. The presence of severe pulmonary hypertension is likely to complicate the course of liver transplantation in patients with PHPAH, even resulting in a fatal outcome $[12,13]$. Nevertheless, it seems feasible that liver transplantation can be performed safely in patients with mild-tomoderate PHPAH [14]. In patients with PHPAH who survive liver transplantation, pulmonary hypertension may [15] or may not [16] reverse. Nowadays, the most rational approach for the treatment of patients with PHPAH seems to be the institution of pharmacological therapy with vasodilators in those patients with a significant reduction in pulmonary vascular tone during an acute challenge with short-acting vasodilators (i.e. i.v. prostacyclin or inhaled NO) [17]. Current recommendations favour treatment with calcium-channel blockers [17], assuming that patients with PHPAH will benefit as much as patients suffering from primary pulmonary hypertension [3]. Nevertheless, calcium-channel blockers may have a deleterious effect on portal hypertension in patients with liver cirrhosis $[4,5]$. However, propranolol, which is currently employed to treat portal hypertension, may provoke an increase in PAP or right atrial pressure. Therefore, it would be desirable to identify a drug that might be beneficial in the treatment of both pulmonary and portal hypertension.

Nitroglycerin, a short-acting organic nitrate, has been shown to reduce PVR in patients with pulmonary hypertension of diverse aetiology when administered by the i.v. route [18]. In addition, in half of the patients in the same study, the effects of $i . v$. nitroglycerin were mimicked by topical preparations of the same drug [18]. Although

Table 1. - Acute and chronic pulmonary and systemic haemodynamic response to vasodilator treatment

\begin{tabular}{|c|c|c|c|c|c|}
\hline & \multirow[b]{2}{*}{ Baseline } & \multicolumn{3}{|c|}{ Acute testing } & \multirow{2}{*}{$\begin{array}{c}\text { Follow-up (6 months) } \\
\text { Is-5-Mn } \\
40 \mathrm{mg} \text { p.o. b.i.d. }\end{array}$} \\
\hline & & $\begin{array}{c}\mathrm{PGI}_{2} \\
4 \mathrm{ng} \cdot \mathrm{kg}^{-1} \cdot \mathrm{min}^{-1}\end{array}$ & $\begin{array}{c}\mathrm{NO} \\
20 \mathrm{ppm}\end{array}$ & $\begin{array}{c}\text { Is-5-Mn } \\
40 \mathrm{mg} \text { p.o. }\end{array}$ & \\
\hline$f_{\mathrm{C}}$ beats $\cdot \mathrm{min}^{-1}$ & 65 & 73 & 70 & 69 & 67 \\
\hline RAP mmHg & 8 & 6 & 6 & 7 & 7 \\
\hline PAP mmHg & 50 & 39 & 37 & 36 & 35.5 \\
\hline$P$ pcw mmHg & 11 & 9 & 10 & 9 & 9 \\
\hline SAP mmHg & 96 & 90 & 95 & 82 & $\mathrm{ND}$ \\
\hline $\mathrm{CO} \mathrm{L} \cdot \mathrm{min}-1$ & 4.10 & 4.96 & 4.6 & 3.9 & 4.7 \\
\hline PVR dynes $\cdot \mathrm{s} \cdot \mathrm{cm}^{-5}$ & 760 & 483 & 469 & 550 & 459 \\
\hline SVR dynes $\cdot \mathrm{s} \cdot \mathrm{cm}^{-5}$ & 1715 & 1353 & 1546 & 1537 & ND \\
\hline$P a, \mathrm{O}_{2} \mathrm{kPa}$ & 9.6 & 10 & 10 & ND & ND \\
\hline$P \mathrm{a}, \mathrm{CO}_{2} \mathrm{kPa}$ & 4.1 & 4 & 4 & ND & ND \\
\hline
\end{tabular}

$\mathrm{PGI}_{2}$ : prostacyclin I2; Is-5-Mn: isosorbide-5-mononitrate; ppm: parts per million; $f \mathrm{C}$ : cardiac frequency; RAP: mean right atrial pressure; PAP: mean pulmonary artery pressure; $P$ pcw: mean pulmonary capillary wedge pressure; SAP: mean systemic arterial pressure; CO: thermodilution cardiac output; PVR: pulmonary vascular resistance; $\mathrm{SVR}$ : systemic vascular resistance. $P \mathrm{a}, \mathrm{O}_{2}$ : arterial oxygen tension; $\mathrm{Pa}_{\mathrm{a}} \mathrm{CO}_{2}$ : arterial carbon dioxide tension; $\mathrm{ND}$ : not done. 
therapy with organic nitrates can be effective in treating patients with severe pulmonary hypertension, the experience with these agents in the treatment of primary pulmonary hypertension is limited [19].

In conclusion, the present case illustrates that longacting organic nitrates could be an adequate therapeutic alternative for the treatment of portal hypertension-associated pulmonary artery hypertension, as they can reduce chronically both portal pressure and pulmonary vascular resistance. Nevertheless, well-designed, prospective trials should be conducted to define the specific role of organic nitrates in portal hypertension-associated pulmonary artery hypertension.

\section{References}

1. Hadengue A, Benhayoun MK, Lebrec D, Benhamou JP. Pulmonary hypertension complicating portal hypertension: prevalence and relation to splanchnic hemodynamics. Gastroenterology 1991; 100: 520-528.

2. Taurà $\mathrm{P}$, Garcá-Valdecasas JC, Beltran J, et al. Moderate primary pulmonary hypertension in patients undergoing liver transplantation. Anesth Analg 1996; 83: 675-680.

3. Rich S, Kaufmann E, Levy PS. The effect of high doses of calcium-channel blockers on survival in primary pulmonary hypertension. $N$ Engl J Med 1992; 327: 76-81.

4. Garcá-Pagán JC, Feu F, Luca A, et al. Nicardipine increases hepatic blood flow and the hepatic clearance of indocyanine green in patients with cirrhosis. $J$ Hepatol 1994; 20: 792-796.

5. Ota K, Shijo H, Kokawa H, et al. Effects of nifedipine on hepatic venous pressure gradient and portal vein flow in patients with cirrhosis. J Gastroenterol Hepatol 1995; 10: 198-204.

6. Navasa M, Chesta J, Bosch J, Rodés J. Reduction of portal pressure by isosorbide-5-mononitrate in patients with cirrhosis. Gastroenterology 1989; 96: 1110-1118.

7. Garcá-Pagán JC, Feu F, Navasa M, et al. Long-term haemodynamic effects on isosorbide-5-mononitrate in patients with cirrhosis and portal hypertension. J Hepatol 1990; 11: 189-195.

8. Lebrec D, Capron JP, Dhumeaux D, Benhamou JP. Pulmonary hypertension complicating portal hypertension. Am Rev Respir Dis 1979; 120: 849-856.

9. Robalino BD, Moodie DS. Association between primary pulmonary hypertension and portal hypertension: analysis of its pathophysiology and clinical, laboratory and hemodynamic manifestations. J Am Coll Cardiol 1991; 17: 492-498.

10. Edwards BS, Weir EK, Edwards WD, Ludwig J, Dykoski RK, Edwards JE. Coexistent pulmonary and portal hypertension: morphologic and clinical features. J Am Coll Cardiol 1987; 10: 1233-1238.

11. Chan T, Palevsky HI, Miller WT. Pulmonary hypertension complicating portal hypertension: findings on chest radiographs. AJR 1988; 151: 909-914.

12. De Wolf AM, Gasior T, Kang Y. Pulmonary hypertension in a patient undergoing liver transplantation. Transplant Proc 1991; 23: 2000-2001.

13. De Wolf AM, Scott VL, Gasior T, Kang Y. Pulmonary hypertension and liver transplantation. Anesthesiology 1993; 78: 213.

14. Plevak D, Krowka M, Rettke S, Dunn W, Southorn P. Successful liver transplantation in patients with mild to moderate pulmonary hypertension. Transplant Proc 1993; 25: 1840

15. Scott V, De Wolf A, Kang Y, et al. Reversibility of pulmonary hypertension after liver transplantation: a case report. Transplant Proc 1993; 25: 1789-1790.

16. Prager MS, Cauldwell CA, Ascher NL, Roberts JP, Wolfe CL. Pulmonary hypertension associated with liver disease is not reversible after liver transplantation. Anesthesiology 1992; 77: 375-378.

17. Mandell MS, Groves BM. Pulmonary hypertension in chronic liver disease. Clin Chest Med 1996; 17: 17-33.

18. Pearl RG, Rosenthal MH, Shroeder JS, Ashton JPA. Acute hemodynamic effects of nitroglycerin in pulmonary hypertension. Ann Intern Med 1983; 99: 9-13.

19. Rubin LJ. Primary pulmonary hyertension: ACCP consensus statement. Chest 1993; 104: 236-250. 